\title{
Immunoelectron Microscopy Shared Facility
}

National Cancer Institute

\section{Source}

National Cancer Institute. Immunoelectron Microscopy Shared Facility. NCI Thesaurus.

Code $C 39425$.

The Immunoelectron Microscopy Shared Resource provides support to Cancer Center investigators in ultrastructural analysis by conventional electron microscopy in conjunction with immunolocalization techniques, including ultra-cryomicrotomy, and internal antigens immuno-labeling. 